\title{
Innovative sacropelvic fixation using iliac screws and triangular titanium implants
}

\author{
Matteo Panico ${ }^{1,2}$ (D) Ruchi D. Chande ${ }^{3} \cdot$ Derek P. Lindsey $^{3} \cdot$ Ali Mesiwala ${ }^{4} \cdot$ Tomaso Maria Tobia Villa $^{1,2}$. \\ Scott A. Yerby ${ }^{3} \cdot$ Enrico Gallazzi $^{5} \cdot$ Marco Brayda-Bruno $^{2} \cdot$ Fabio Galbusera $^{2}$
}

Received: 17 May 2021 / Revised: 19 August 2021 / Accepted: 21 September 2021 / Published online: 25 September 2021

(c) The Author(s) 2021

\begin{abstract}
Purpose Sacropelvic fixation is frequently used in combination with thoracolumbar instrumentation for the correction of severe spinal deformities. The purpose of this study was to explore the effects of the triangular titanium implants on the iliac screw fixation. Our hypothesis was that the use of triangular titanium implants can increase the stability of the iliac screw fixation.

Methods Three T10-pelvis instrumented models were created: pedicle screws and rods in T10-S1, and bilateral iliac screws (IL); posterior fixation and bilateral iliac screws and triangular implants inserted bilaterally in a sacro-alar-iliac trajectory (IL-Tri-SAI); posterior fixation and bilateral iliac screws and two bilateral triangular titanium implants inserted in a lateral trajectory (IL-Tri-Lat). Outputs of these models, such as hardware stresses, were compared against a model with pedicle screws and rods in T10-S1 (PED).

Results Sacropelvic fixation decreased the L5-S1 motion by 75-90\%. The motion of the SIJ was reduced by $55-80 \%$ after iliac fixation; the addition of triangular titanium implants further reduced it. IL, IL-Tri-SAI and IL-Tri-Lat demonstrated lower S1 pedicle stresses with respect to PED. Triangular implants had a protective effect on the iliac screw stresses.

Conclusion Sacropelvic fixation decreased L5-S1 range of motion suggesting increased stability of the joint. The combination of triangular titanium implants and iliac screws reduced the residual flexibility of the sacroiliac joint, and resulted in a protective effect on the $\mathrm{S} 1$ pedicle screws and iliac screws themselves. Clinical studies may be performed to demonstrate applicability of these FEA results to patient outcomes.
\end{abstract}

Keywords Sacropelvic fixation · Long thoracolumbar fixation · Iliac screws $\cdot$ Triangular implants $\cdot$ S2 alar-iliac screws

\section{Introduction}

Matteo Panico

matteo.panico@polimi.it

1 Department of Chemistry, Materials and Chemical Engineering "Giulio Natta", Politecnico di Milano, 20133 Milan, Italy

2 IRCCS Istituto Ortopedico Galeazzi, Milan, Italy

3 SI-BONE, Inc., Santa Clara, CA, USA

4 Southern California Center for Neuroscience and Spine, Pomona, CA, USA

5 ASST Gaetano Pini: Azienda Socio Sanitaria Territoriale Gaetano Pini, Milan, Italy
Sacropelvic fixation is frequently used in combination with long thoracolumbar fixation for treating adult spinal deformities in order to reduce specific complications including pseudarthrosis of the L5-S1 joint, and implant failure and loosening. In several cases, lumbosacral fixation with pedicle screws at the sacrum offers inadequate fixation with respect to the significant biomechanical shear forces across the lumbosacral junction, which is evident in published rates of lumbosacral pseudarthrosis as high as $33 \%$ with pullout of sacral pedicle screws approaching $44 \%[1,2]$. Supplementing lumbosacral pedicle screw fixation with sacropelvic fixation instrumentation results in higher construct stability and lower stresses of $\mathrm{S} 1$ pedicle screws [3,4], which are the most susceptible to failure and loosening [5-7]. However, achieving a successful fixation of the lumbosacral junction remains 
a challenging task even when supplementary sacropelvic fixation is performed due to the low mechanical strength of bone tissue in the sacrum and to the aforementioned large loads to which the sacropelvic implants are subjected [3, 4, $8,9]$. Therefore, determination of the most effective biomechanical solutions for sacropelvic fixation assumes a critical importance.

Although several methods for sacropelvic fixation have been described, iliac (IL) and S2 alar-iliac (S2AI) screws are currently the most commonly used methods $[9,10]$. The first surgical method that incorporated the ilium was the Galveston technique developed by Allen and Ferguson [11], which was based on $L$-shaped rods spanning the thoracolumbar fixation and the ilium itself, but was associated with a high pseudarthrosis rate (36\%) [12]. IL screw fixation, which consists of special connectors joining the distal end of the longitudinal rod to screws entering the ilium at the posterior superior iliac spine [13], represented an advancement over the Galveston technique in terms of pseudarthrosis risk $(14 \%)[12,14]$. Another technique that was introduced more recently and was then widely adopted is the fixation with S2AI screws, which was first described in 2007 by Sponseller and Kebaish and validated by biomechanical studies in human cadavers [15]. S2AI screws are inserted at the S2 level from the sacrum to the ilium, through the SIJ, and they are connected to the posterior rods without connectors [16-18].

Clinical studies have reported marked differences between the post-operative outcomes of long thoracolumbar fixation using iliac versus S2AI screws. For example, symptomatic screw prominence has been associated with iliac screws [19]. Further, in comparison with S2AI screws, iliac screws have higher rates of reoperation and surgical site infection [19]. With regard to S2AI screws, their trajectory passes in the proximity of important neurological and vascular structures [20]. For this reason, the implantation of S2AI tends to be more technically demanding relative to iliac screws. Additionally, the S2AI technique demonstrated longer reoperation time in the case of failure of the initially placed implants [16]. However, the medial position of S2AI screws allows linkage to the rods without the need of an additional connector as with iliac screws, and may improve the stability of the construct. Currently, both techniques are used clinically and have been compared in different finite element and in vitro studies $[4,16]$.

Triangular titanium implants (iFuse Implant System, SI-BONE, Inc., Santa Clara, CA, USA) have been used to treat painful SIJ in cases of degenerative sacroiliitis or sacroiliac joint disruption and early degeneration following long fusion to the sacrum with good clinical success [21]. In a previous finite element study, we compared two innovative configurations in which triangular titanium implants were used in combination with S2AI screws and compared them with the standard S2AI fixation. The study revealed that supplementing S2AI screws with triangular implants has a protective effect on the S2AI screws themselves by reducing the maximal stresses [22]. The combined use of iliac screws and triangular titanium implants was, however, not explored in any previous study. This combination can be a potential alternative to enhance sacropelvic fixation.

This study sought to investigate innovative configurations in which triangular titanium implants supplement standard sacropelvic fixation with iliac screws. Our hypothesis was that the addition of triangular titanium implants to traditional sacropelvic fixation with iliac screws would result in (1) decreased L5-S1 and SI joint motion thereby improving the stability of both joints and (2) a reduction of hardware stresses thus reducing the chances of hardware loosening or failure. To address these aims, we built instrumented models based on an existing validated intact model with pedicle screws and rods, bilaterally placed iliac screws, and bilaterally placed triangular titanium implants inserted either in a lateral or in sacro-alar-iliac (SAI) trajectory. To compare the various configurations, the ranges of motion of L5-S1 and SIJ, as well as the stresses in the lumbosacral and sacropelvic instrumentation were evaluated.

\section{Materials and methods}

\section{Finite element models}

A finite element model of T10-pelvis resulting from the combination of a model of pelvis (sacrum and coxal bones) and L5 vertebra with a model of the T10-L4 region, developed and validated in a previous study, was employed [22]. In brief, the existing model of the pelvis and L5 vertebra represented the anatomy of a female adult subject acquired by means of CT scans. The T10-L4 model represents the anatomy of a healthy subject in standing acquired by means of biplanar radiographs. For both models, the patient gave informed consent in written form for scientific and educational use of the images. Ethics approval was not required. The two models were combined by means of a kinematic coupling. A detailed description of meshes, element types, material properties, as well as validation of the intact model is reported elsewhere [22].

The intact model was used to create three different fixation configurations: (1) posterior rods and pedicle screws in the thoracolumbar spine and $\mathrm{S} 1$, and bilateral iliac screws (IL); (2) posterior rods and pedicle screws in the thoracolumbar spine and S1, and bilateral iliac screws and triangular implants inserted bilaterally in a SAI trajectory (IL-Tri-SAI); (3) posterior rods and pedicle screws in the thoracolumbar spine and $\mathrm{S} 1$, and bilateral iliac screws and two bilateral triangular implants inserted in a lateral 
trajectory (IL-Tri-Lat) (Fig. 1). These configurations were then compared alongside another configuration that was also developed from the intact model and described previously [22]: posterior rods and pedicle screws in the thoracolumbar spine and S1 (PED) (Fig. 1).

In all models, the triangular titanium implants were not connected to the posterior rods and had a length of $50-70 \mathrm{~mm}$ and an inscribed circular diameter of $7 \mathrm{~mm}$; the posterior rods were modeled as beam elements with circular section and had a diameter of $5.5 \mathrm{~mm}$; pedicle screws had a length of $40 \mathrm{~mm}$ and a diameter of $6.5 \mathrm{~mm}$; the iliac screws had a length of $85 \mathrm{~mm}$ and a diameter of $8.0 \mathrm{~mm}$. All implants were modeled as having the material properties of titanium (elastic modulus of $110 \mathrm{GPa}$ and Poisson's ratio of 0.3$)$.

\section{Interactions and simulations}

Similar to the previous studies $[3,22]$, the interaction between pedicle screws (T10-L5) and thoracolumbar vertebrae was modeled by means of embedded elements, which consist of a kinematic coupling between the external nodes of the screws and the adjacent nodes in the bone tissue in order to impose zero relative displacements between pedicle screws and bone. In the sacrum and ilium, spring elements between the external nodes of the implants and the nodes in the surrounding bone were used to define the interaction between bone and $\mathrm{S} 1$ pedicle screws, iliac screws, and triangular implants in order to simulate the micromovements of these implants under the effect of loading. The stiffness of the springs was calibrated in order to match the mechanical response of the bone-implant construct as measured in experimental tests [3].

All the instrumented models were used to simulate pure moments of $7.5 \mathrm{Nm}$ in flexion, extension, left and right lateral bending, and left and right axial rotation. The moments were applied to the upper endplate of the T10 vertebra through a set of rigid beam elements. Double-leg stance was simulated by constraining all nodes belonging to the bilateral acetabula of the finite element models. According to this, six simulations for each fixation configuration were run resulting in a total of 18 simulations.

\section{Model metrics}

A quantitative comparison among the instrumented models was performed relative to the fixation configuration with only pedicle screws (PED). The outputs analyzed in this comparison were: (1) range of motion (ROM) of L5-S1 and SIJ with respect to the corresponding intact value; (2) the maximal von Mises stresses in S1 pedicle screws; (3) the maximal von Mises stresses in iliac screws; (4) the maximal stresses in the posterior rods between the pedicle screws in L5 and S1 (i.e., lumbosacral junction).

\section{Results}

\section{Range of motion}

The relative ROM of L5-S1 with respect to the intact condition showed a similar behavior among IL, IL-Tri-SAI and
Fig. 1 The four configurations of the instrumentation in the sacropelvic region (left-posterior view of sacropelvis; right-lateral view of sacropelvis): a pedicle screw fixation (PED); b posterior fixation and iliac fixation (IL); $\mathbf{c}$ same as (b) bilaterally supplemented by a triangular titanium implant placed in a sacro-alar-iliac trajectory (IL-Tri-SAI); d same as (b) supplemented by two bilateral triangular titanium implants (IL-Tri-Lat). Rods not shown

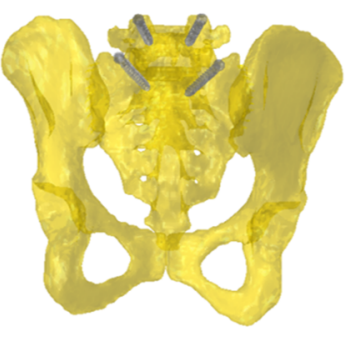

(a) PED

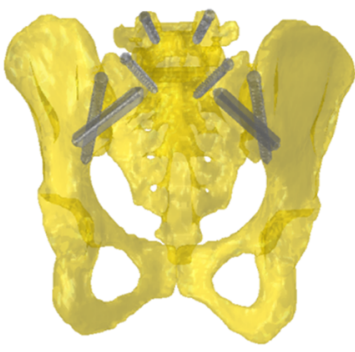

(c) IL-Tri-SAI
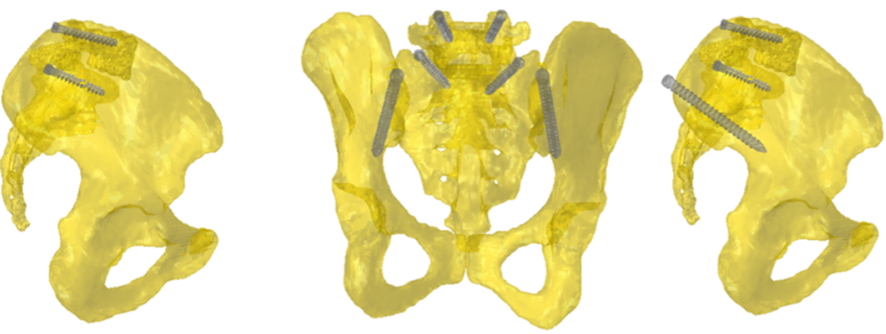

(b) IL
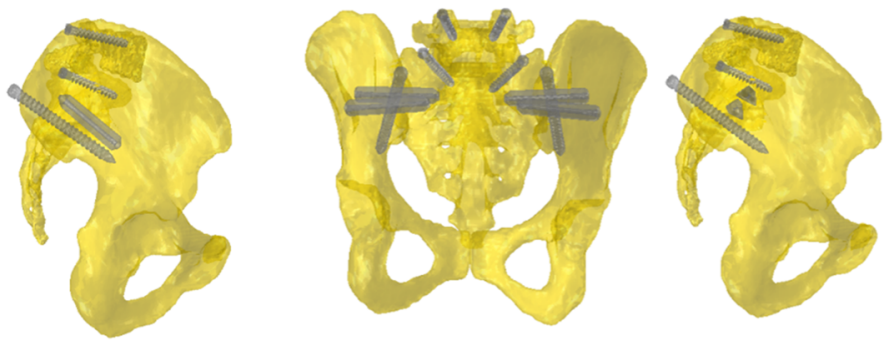

(d) IL-Tri-Lat 
IL-Tri-Lat for all the three loading conditions; the same was true for the relative ROM of the SIJ (Fig. 2). At L5-S1, sacropelvic fixation resulted in a marked decrease in ROM (between 75 and 90\%) with respect to PED, especially in lateral bending. At the SIJ, the ROM after fixation was lower than that of the intact condition in all instrumented configurations. However, PED resulted in only a minor decrease in ROM (between 5 and 15\%), whereas sacropelvic fixation induced a further decrease in the motion of the sacroiliac joint. IL-Tri-SAI demonstrated the lowest relative values (between 10 and 20\%). IL-Tri-Lat showed no major differences from the IL-Tri-SAI. IL resulted in a reduction between 50 and $80 \%$ of the initial flexibility.

\section{S1 pedicle screws}

Due to the symmetry in the boundary conditions, the maximal von Mises stresses in the S1 pedicle screws on the right side were on the same order of magnitude as those on the left side; thus, the latter are shown (Fig. 3). Compared to $\mathrm{PED}$, the three configurations including sacropelvic fixation resulted in significantly lower maximum stresses in the pedicle screws. For IL versus PED, a reduction from 133-319 to 28-50 MPa was predicted. For IL-Tri-SAI and IL-Tri-Lat, minor differences in the maximal stresses with respect to the IL configuration were predicted.

\section{Iliac screws}

Similar to $\mathrm{S} 1$ pedicle screws, the maximal von Mises stresses in iliac screws on the right side were in the same range of those on the left side, thus data for the left side are presented (Fig. 3). Adding the triangular implants had a protective effect on the maximal stresses observed in the iliac screws (up to 55\%), except during lateral bending. When the triangular implants were inserted in a sacroalar-iliac trajectory (IL-Tri-SAI), the smallest values of maximal stresses were found, especially in axial rotation (15 MPa). IL-Tri-Lat showed minor differences with respect to IL-Tri-SAI.
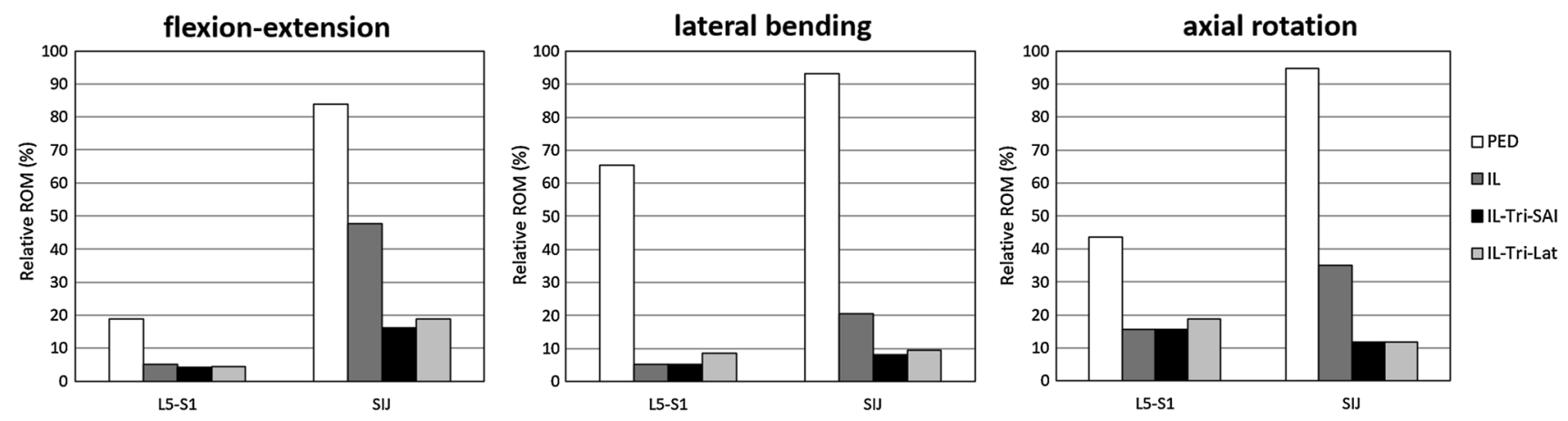

Fig. 2 Predicted ranges of motion of L5-S1 and sacroiliac joints (SIJ) for the four instrumented configurations (PED, IL, IL-Tri-SAI, IL-Tri-Lat) with respect to the intact condition, in flexion-extension (left), lateral bending (middle) and axial rotation (right)
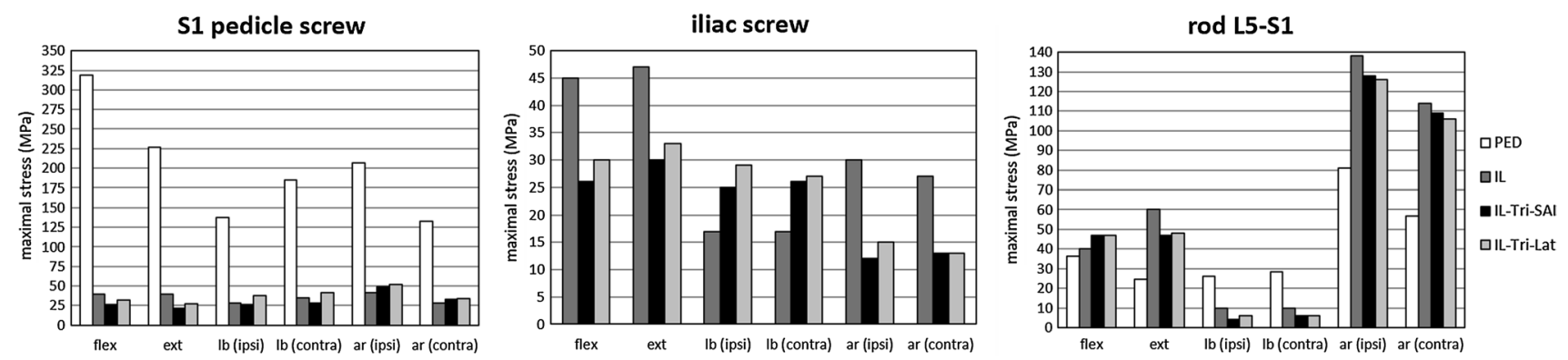

Fig. 3 Stresses in the left sacropelvic instrumentation and in the left posterior rods. Maximal stresses in the S1 pedicle screws (left); maximal stresses in the IL screws (center); maximal stresses in the posterior rods in the portion between the L5 and the S1 pedicle screws (right) predicted for the four instrumented configurations (PED, IL, IL-Tri-SAI, IL-Tri-Lat). "flex": flexion; "ext": extension; "lb (ipsi)": lateral bending in the ipsilateral direction (the same side of the implant of interest); "lb (contra)": lateral bending in the contralateral direction; "ar (ipsi)": axial rotation in the ipsilateral direction (the same side of the implant of interest); "ar (contra)": axial rotation in the contralateral direction 


\section{Posterior rods}

As for S1 pedicle screws and iliac screws, the maximal von Mises stresses in the posterior rods on the right and left side were comparable due to the symmetry in the boundary conditions (Fig. 3). With respect to simple pedicle screw fixation (PED), adding iliac screws had a negative effect on the maximal stresses observed on the posterior rods, except during lateral bending. The largest differences were found in axial rotation for both directions, with stress increments up to $50 \%$. Adding triangular implants did not change the maximal stresses in the posterior rods in a substantial way.

\section{Discussion}

In this study, we compared the biomechanical effect of two innovative sacropelvic fixation techniques, in which iliac screws were supplemented with triangular titanium implants, in conjunction with thoracolumbar pedicle screw fixation. Results were evaluated in terms of residual flexibility of L5-S1 and SIJ, and von Mises stresses in the hardware. In general, the results demonstrated that standard sacropelvic fixation technique (IL) reduced the flexibility of L5-S1 and SIJ. These findings closely confirmed the measurements published in an in vitro paper [22] in which pedicle screw fixation in the lumbosacral spine alone or supplemented by either iliac screws or S2 alar-iliac screws were tested in 21 human specimens. The titanium implants did not have an evident effect on the stability of L5-S1 for all the loading conditions but further reduced the flexibility of the SIJ, consistent with our previous findings [3, 4].

Stresses in the instrumentation were found to be significantly affected by the different sacropelvic fixation techniques. In line with previous studies, IL reduced the stresses in $\mathrm{S} 1$ pedicle screws $[4,24,25]$. This finding demonstrates that pelvic fixation with iliac screws is effective in protecting S1 pedicle screws from mechanical failure. The triangular titanium implants had a negligible protective effect on the maximal stresses of the $\mathrm{S} 1$ pedicle stresses, and the stresses did not worsen [3]. Von Mises stresses in iliac screws were lower after sacroiliac fixation in flexion/extension and axial rotation with triangular implants with respect to the standard configuration (IL). The lowest stress in the iliac screws was found when the triangular implants were implanted in a sacro-alar-iliac trajectory (IL-Tri-SAI). In the posterior rods, von Mises stresses were found to be highest in the IL configuration. This negative effect of the IL screws on the rods has also been reported in several studies $[3,4,26]$. The triangular implants did not have an evident effect on the rod stresses, consistent with previous studies [3, 4, 22].

The iliac screw configurations discussed here were compared to corresponding configurations using S2AI screws (S2AI, Tri-SAI, and Tri-Lat), which were described previously [22]. In line with previous studies, negligible differences were found in terms of relative ROM between the two types of sacropelvic fixation techniques [23, 27]. Von Mises stresses in S1 pedicle screws were higher after sacroiliac fixation with S2AI screws with respect to IL screws (Table 1) [22]. Von Mises stresses in the posterior rods were found to be higher in the configurations with iliac screws with respect to the configurations with S2 alar-iliac screws (Table 2) [22]. These findings confirmed those of our previous finite element models $[3,4]$ as well as those of a published in vitro investigation [26]. In summary, configurations with IL screws resulted in the lowest risk of S1 pedicle screw failure and in the higher risk of rod failure with respect to the S2AI configurations.

Although we built sophisticated models with the aim of enhancing the accuracy of the predictions, this study still has several limitations. The intact model includes several simplifications in the intervertebral disks and facet joints; however, the validation of the ROMs [22] demonstrated the plausibility of the intact model in terms of flexibility. Regarding the boundary conditions, a simplified loading scenario replicating a double-leg stance in combination with pure moments was employed, whereas complex loads and motions due to the body weight and muscles were not modeled. These boundary conditions were used in a number of previous studies and the values of flexibility, intradiscal pressures and
Table 1 Stresses in the left sacropelvic instrumentation. Maximal stresses in the $\mathrm{S} 1$ pedicle screws predicted for the configurations with iliac screws (IL, IL-Tri-SAI and IL-Tri-Lat) and with S2 alar-iliac screws (S2AI, Tri-SAI and Tri-Lat) [24]

\begin{tabular}{|c|c|c|c|c|c|c|}
\hline \multirow[b]{3}{*}{ Load } & \multicolumn{6}{|c|}{ Maximu stress (Mpa)—pedicle screw (Left) } \\
\hline & \multicolumn{3}{|c|}{ Ilac screw configurations } & \multicolumn{3}{|c|}{ S2AI screw configurations } \\
\hline & $\mathrm{IL}$ & IL-Tri-SAI & IL-Tri-Lat & S2AI & Tri-SAI & Tri-Lat \\
\hline Flexion & 40 & 26 & 32 & 88 & 71 & 70 \\
\hline Extension & 40 & 22 & 27 & 67 & 65 & 62 \\
\hline Axial rotation-left & 42 & 49 & 52 & 85 & 75 & 75 \\
\hline Axial rotation-right & 28 & 33 & 34 & 60 & 60 & 65 \\
\hline Lateral bending-left & 28 & 26 & 38 & 88 & 90 & 82 \\
\hline Lateral bending_right & 35 & 28 & 42 & 95 & 90 & 92 \\
\hline
\end{tabular}


Table 2 Stresses in the left posterior rods. Maximal stresses in the posterior rods in the portion between the L5 and the $\mathrm{S} 1$ pedicle screws predicted for the configurations with iliac screws (IL, IL-Tri-SAI and IL-Tri-Lat) and with S2 alariliac screws (S2AI, Tri-SAI and Tri-Lat) [24]

\begin{tabular}{|c|c|c|c|c|c|c|}
\hline \multirow[b]{3}{*}{ Load } & \multicolumn{6}{|c|}{ Maximu stress (Mpa)—Rod (Left) } \\
\hline & \multicolumn{3}{|c|}{ Ilac screw configurations } & \multicolumn{3}{|c|}{ S2AI screw configurations } \\
\hline & IL & IL-Tri-SAI & IL-Tri-Lat & S2AI & Tri-SAI & Tri-Lat \\
\hline Flexion & 40 & 47 & 47 & 35 & 39 & 38 \\
\hline Extension & 60 & 47 & 48 & 37 & 38 & 40 \\
\hline Axial rotation-left & 138 & 128 & 126 & 117 & 100 & 114 \\
\hline Axial rotation-right & 114 & 109 & 106 & 93 & 95 & 90 \\
\hline Lateral bending—left & 10 & 4 & 6 & 16 & 11 & 13 \\
\hline Lateral bending_right & 10 & 6 & 6 & 15 & 13 & 13 \\
\hline
\end{tabular}

instrumentation strains obtained by the intact model are very similar to those measured in vivo by means of telemeterized implants [28-30], thus demonstrating the validity of simulating physiological loads with pure moments. Moreover, only one size for each type of screw, as opposed to a range of lengths and diameters, was selected based on the suggestion of the surgeon investigators. Other simplifications were adopted in the modeling approach for the instrumentation, in which posterior rods and connectors (in the iliac screw configurations) were simulated as beam elements, and kinematic constraints were employed to model tulips. Other technical limitations are reported in detail in our previous finite element studies $[3,22]$. It should be noted that the majority of patients will have also an interbody fusion at L5-S1 in combination with spinal and sacropelvic fixation, which was not considered in the present study. The interbody fusion at L5-S1 is expected to affect the lumbosacral flexibility as well as the stresses in the implants, and will be modeled in a future study.

The IL configurations presented here demonstrated increased stability of the L5-S1 and sacroiliac joints, as well as decreased stresses in S1 pedicle screws. Clinical studies could be performed to confirm whether the results of this study translate to positive patient outcomes; and further, such studies could assess the ease of placement of the described configurations. While the experimental stress reduction on the $\mathrm{S} 1$ pedicle screws observed with both the IL-Tri-SAI and IL-Tri-Lat could be of extreme value in preventing mechanical failure at L5-S1 junction, obtaining the correct configuration surgically could be difficult given the overlapping anatomical trajectories of the implants; it has been reported that the presence of two laterally placed triangular implants can impact the trajectory of both S2AI and standard iliac screws [31]. However, this technical issue could be overcome by placing the triangular implants after the iliac or S2AI screws. On the contrary, placement of the triangular implant in a SAI trajectory could offer some advantages while still providing a similar amount of stress reduction on $\mathrm{S} 1$ pedicle screws when compared to the lateral trajectory: first, it could be carried out through the same posterior approach, thus avoiding an additional surgical stage; second, the trajectory could be planned more easily to avoid impaction with the iliac screw. Even though detailed cadaveric studies might be needed to identify the anatomical landmarks and trajectory for implant placement, this innovative approach warrants careful clinical evaluation.

It should be noted that augmenting pelvic fixation with additional implants may have socio-economic impacts. It is reasonable, however, to conclude that the impact of a revision surgery due to a less stable construct or broken hardware would be increased for the patient and overall medical system. Future investigations could, therefore, also address the cost-effectiveness of the configurations proposed in this study.

In the current study, a biomechanical evaluation of novel sacropelvic fixation techniques using iliac screws and triangular titanium implants was performed. In general, this finite element study confirmed that sacropelvic fixation in combination with long thoracolumbar instrumentation reduced L5-S1 motion and reduced hardware stresses, suggesting a potential for reduced pseudarthrosis at L5-S1 and risk of screw breakage, respectively. The triangular implants further reduced motion of the SIJ and reduced the stresses in the iliac screws themselves, suggesting increased stability of the SIJ, reduced risk of screw failure, and a possible role in patients needing reinforced fixation; clinical evaluation may be performed to confirm the applicability of results to patient outcomes. From the comparison between the configurations with iliac screws and the corresponding configurations using S2AI screws, which both take possible micromovements between bone and instrumentation into account, we can conclude that fixation with iliac screws reduces the stresses in $\mathrm{S} 1$ pedicle screws and thus their risk of mechanical failure, but has a negative effect on the rod stresses with respect to S2AI.

Acknowledgements The study has been funded by SI-BONE, Inc., Santa Clara, CA, USA. 
Author contributions Conception and design: RDC, DPL, AM, SAY, MBB, FG; Acquisition and data: MP, RDC, DPL, TMTV, FG; Analysis and interpretation of data: MP, RDC, DPL, AM, SAY, MBB, EG, TMTV, FG; Drafting of the manuscript: MP, RDC, FG; Critical revision of the manuscript for important intellectual content: MP, RDC, DPL, AM, SAY, MBB, EG, TMTV, FG.

Funding Open access funding provided by Politecnico di Milano within the CRUI-CARE Agreement. The study was funded by SIBONE, Inc and partially supported by the Italian Ministry of Health ("Ricerca Corrente").

Availability of data and material All data are available from the corresponding author upon reasonable request.

\section{Declarations}

Conflict of interest D.P.L. is an employee of SI-BONE, has stock options/stock in SI-BONE, and has a patent US Patent 10,194,962 and a patent US Patent 9,662,157. S.A.Y. is an employee of SI-BONE, reports grants from SI-BONE, and has a patent 20200268525 pending. R.D.C. is an employee of SI-BONE and has stock options/stock in SIBONE. A.M. reports paid consultant and shareholder from SI-BONE and has a patent implants for spinal fixation or fusion with royalties paid. F.G. reports grants from SI-BONE.

Open Access This article is licensed under a Creative Commons Attribution 4.0 International License, which permits use, sharing, adaptation, distribution and reproduction in any medium or format, as long as you give appropriate credit to the original author(s) and the source, provide a link to the Creative Commons licence, and indicate if changes were made. The images or other third party material in this article are included in the article's Creative Commons licence, unless indicated otherwise in a credit line to the material. If material is not included in the article's Creative Commons licence and your intended use is not permitted by statutory regulation or exceeds the permitted use, you will need to obtain permission directly from the copyright holder. To view a copy of this licence, visit http://creativecommons.org/licenses/by/4.0/.

\section{References}

1. DePasse JM, Valdes M, Palumbo MA, Daniels AH, Eberson CP (2018) S-1 alar/iliac screw technique for spinopelvic fixation. J Neurosurg Spine 28(5):543-547. https://doi.org/10.3171/2017.8. SPINE16904

2. Lombardi JM, Shillingford JN, Lenke LG, Lehman RA (2018) Sacropelvic fixation: When, why, how? Neurosurg Clin N Am 29(3):389-397. https://doi.org/10.1016/j.nec.2018.02.001

3. Galbusera F, Casaroli G, Chande R, Lindsey D, Villa T, Yerby S, Mesiwala A, Panico M, Gallazzi E, Brayda-Bruno M (2020) Biomechanics of sacropelvic fixation: a comprehensive finite element comparison of three techniques. Eur Spine J 29(2):295-305. https://doi.org/10.1007/s00586-019-06225-5

4. Casaroli G, Galbusera F, Chande R, Lindsey D, Mesiwala A, Yerby S, Brayda-Bruno M (2019) Evaluation of iliac screw, S2 alar-iliac screw and laterally placed triangular titanium implants for sacropelvic fixation in combination with posterior lumbar instrumentation: a finite element study. Eur Spine J 28(7):17241732. https://doi.org/10.1007/s00586-019-06006-0

5. Fleischer GD, Kim YJ, Ferrara LA, Freeman AL, Boachie-Adjei $\mathrm{O}$ (2012) Biomechanical analysis of sacral screw strain and range of motion in long posterior spinal fixation constructs: effects of lumbosacral fixation strategies in reducing sacral screw strains. Spine 37(3):E163-E169. https://doi.org/10.1097/BRS.0b013 e31822ce9a7

6. Kleck CJ, Illing D, Lindley EM, Noshchenko A, Patel VV, Barton C, Baldini T, Cain C, Burger EL (2017) Strain in posterior instrumentation resulted by different combinations of posterior and anterior devices for long spine fusion constructs. Spine deformity 5(1):27-36. https://doi.org/10.1016/j.jspd.2016.09.045

7. Sutterlin CE 3rd, Field A, Ferrara LA, Freeman AL, Phan K (2016) Range of motion, sacral screw and rod strain in long posterior spinal constructs: a biomechanical comparison between S2 alar iliac screws with traditional fixation strategies. J Spine Surg (Hong Kong) 2(4):266-276. https://doi.org/10.21037/jss.2016.11. 01

8. Cho W, Mason JR, Smith JS, Shimer AL, Wilson AS, Shaffrey CI, Shen FH, Novicoff WM, Fu KM, Heller JE, Arlet V (2013) Failure of lumbopelvic fixation after long construct fusions in patients with adult spinal deformity: clinical and radiographic risk factors: clinical article. J Neurosurg Spine 19(4):445-453. https://doi.org/ 10.3171/2013.6.SPINE121129

9. Guler UO, Cetin E, Yaman O, Pellise F, Casademut AV, Sabat MD, Alanay A, Grueso FS, Acaroglu E (2015) Sacropelvic fixation in adult spinal deformity (ASD); a very high rate of mechanical failure. Eur Spine J 24(5):1085-1091. https://doi.org/10.1007/ s00586-014-3615-1

10. Ilyas H, Place H, Puryear A (2015) A comparison of early clinical and radiographic complications of iliac screw fixation versus S2 Alar Iliac (S2AI) fixation in the adult and pediatric populations. J Spinal Disord Tech 28(4):E199-E205. https://doi.org/10.1097/ BSD.0000000000000222

11. Allen BL Jr, Ferguson RL (1984) The Galveston technique of pelvic fixation with L-rod instrumentation of the spine. Spine 9(4):388-394. https://doi.org/10.1097/00007632-19840 5000-00011

12. Emami A, Deviren V, Berven S, Smith JA, Hu SS, Bradford DS (2002) Outcome and complications of long fusions to the sacrum in adult spine deformity: luque-galveston, combined iliac and sacral screws, and sacral fixation. Spine 27(7):776-786. https:// doi.org/10.1097/00007632-200204010-00017

13. Kuklo TR, Bridwell KH, Lewis SJ, Baldus C, Blanke K, Iffrig TM, Lenke LG (2001) Minimum 2-year analysis of sacropelvic fixation and L5-S1 fusion using S1 and iliac screws. Spine 26(18):1976-1983. https://doi.org/10.1097/00007632-20010 9150-00007

14. Fridley J, Fahim D, Navarro J, Wolinsky JP, Omeis I (2014) Freehand placement of iliac screws for spinopelvic fixation based on anatomical landmarks: technical note. Int J Spine Surg 8:3. https:// doi.org/10.14444/1003

15. O'Brien JR, Yu W, Kaufman BE, Bucklen B, Salloum K, Khalil S, Gudipally M (2013) Biomechanical evaluation of S2 alar-iliac screws: effect of length and quad-cortical purchase as compared with iliac fixation. Spine 38(20):E1250-E1255. https://doi.org/ 10.1097/BRS.0b013e31829e17ff

16. Ishida W, Elder BD, Holmes C, Goodwin CR, Lo SF, Kosztowski TA, Bydon A, Gokaslan ZL, Wolinsky JP, Sciubba DM, Witham TF (2016) S2-Alar-Iliac screws are associated with lower rate of symptomatic screw prominence than iliac screws: radiographic analysis of minimal distance from screw head to skin. World Neurosurg 93:253-260. https://doi.org/10.1016/j.wneu.2016.06.042

17. Sponseller P (2007) The S2 portal to the ilium. Semin Spine Surg 2:83-87

18. Kebaish KM (2010) Sacropelvic fixation: techniques and complications. Spine 35(25):2245-2251. https://doi.org/10.1097/BRS. 0b013e3181f5cfae 
19. Shen FH, Mason JR, Shimer AL, Arlet VM (2013) Pelvic fixation for adult scoliosis. Eur Spine J 22(Suppl 2):S265-S275. https:// doi.org/10.1007/s00586-012-2525-3

20. Laratta JL, Shillingford JN, Meredith JS, Lenke LG, Lehman RA, Gum JL (2018) Robotic versus freehand S2 alar iliac fixation: in-depth technical considerations. J Spine Surg (Hong Kong) 4(3):638-644. https://doi.org/10.21037/jss.2018.06.13

21. Schroeder JE, Cunningham ME, Ross T, Boachie-Adjei O (2014) Early results of sacro-iliac joint fixation following long fusion to the sacrum in adult spine deformity. HSS J 10(1):30-35. https:// doi.org/10.1007/s11420-013-9374-4

22. Panico M, Chande RD, Lindsey DP, Mesiwala A, Villa T, Yerby SA, Brayda-Bruno M, Galbusera F (2020) The use of triangular implants to enhance sacropelvic fixation: a finite element investigation. Spine J 20(10):1717-1724. https://doi.org/10.1016/j. spinee.2020.05.552

23. Cunningham BW, Sponseller PD, Murgatroyd AA, Kikkawa J, Tortolani PJ (2019) A comprehensive biomechanical analysis of sacral alar iliac fixation: an in vitro human cadaveric model. J Neurosurg Spine 30(3):367-375. https://doi.org/10.3171/2018.8. SPINE18328

24. Cunningham BW, Sefter JC, Hu N, Kim SW, Bridwell KH, McAfee PC (2010) Biomechanical comparison of iliac screws versus interbody femoral ring allograft on lumbosacral kinematics and sacral screw strain. Spine 35(6):E198-E205. https://doi.org/10. 1097/BRS.0b013e3181c142bf

25. Lebwohl NH, Cunningham BW, Dmitriev A, Shimamoto N, Gooch L, Devlin V, Boachie-Adjei O, Wagner TA (2002) Biomechanical comparison of lumbosacral fixation techniques in a calf spine model. Spine 27(21):2312-2320. https://doi.org/10.1097/ 00007632-200211010-00003

26. Hlubek RJ, Godzik J, Newcomb A, Lehrman JN, de Andrada B, Bohl MA, Farber SH, Kelly BP, Turner JD (2019) Iliac screws may not be necessary in long-segment constructs with L5-S1 anterior lumbar interbody fusion: cadaveric study of stability and instrumentation strain. Spine J 19(5):942-950. https://doi.org/10. 1016/j.spinee.2018.11.004

27. Hoernschemeyer DG, Pashuck TD, Pfeiffer FM (2017) Analysis of the s2 alar-iliac screw as compared with the traditional iliac screw: Does it increase stability with sacroiliac fixation of the spine? Spine J 17(6):875-879. https://doi.org/10.1016/j.spinee. 2017.02.001

28. Dreischarf M, Rohlmann A, Bergmann G, Zander T (2011) Optimised loads for the simulation of axial rotation in the lumbar spine. J Biomech 44(12):2323-2327. https://doi.org/10.1016/j. jbiomech.2011.05.040

29. Rohlmann A, Zander T, Rao M, Bergmann G (2009) Applying a follower load delivers realistic results for simulating standing. $\mathrm{J}$ Biomech 42(10):1520-1526. https://doi.org/10.1016/j.jbiomech. 2009.03.048

30. Rohlmann A, Zander T, Rao M, Bergmann G (2009) Realistic loading conditions for upper body bending. J Biomech 42(7):884890. https://doi.org/10.1016/j.jbiomech.2009.01.017

31. Laratta JL, Lin JD, Shillingford JN, Hardy NE, Reddy H, Lehman RA (2017) Obstructed spinopelvic fixation in the setting of a triangular titanium sacroiliac fusion implant: a case description. J Spine Surg (Hong Kong) 3(4):732-735. https://doi.org/10.21037/ jss.2017.11.11

Publisher's Note Springer Nature remains neutral with regard to jurisdictional claims in published maps and institutional affiliations. 